\title{
Holistic Healing and Medical Pluralism
}

\section{K. R. Sethuraman *}

Holistic healing is rarely discussed in "Western Medicine" unlike other disciplines like Medical Sociology, Medical Anthropology and traditional systems of Medicine (AYUSH disciplines). Holistic Healing is " to achieve or acquire wholeness as a person. The wholeness involves physical, emotional, intellectual, social, and spiritual aspects of human experience." (TR Egnew. MD)

The types of Healing include, Spontaneous (natural) healing, Technological healing (based on active medications or procedures) and Interpersonal (faith-based) healing. Wickenburg Consensus in 1988 has estimated that rational therapy accounted for only $20 \%$ of healing process; the remainder comes from Placebo effect, Hawthorne effect and Spiritual factor.

I. Placebo \& Nocebo effects are two sides of a coin. Placebo is "I shall please" in Latin. Nocebo is "I shall harm" in Latin. Placebo response rate is from 15\% to 58\% with a mean of 35\% (Prof Beecher of Harvard in 1955). Prof HM Spiro of Yale (1986) has said, "In clinical trials of duodenal ulcer, the placebo benefit was up to $70 \%$ and a mean of 50\%". Ted Kaptchuk (1998) a Harvard Professor says, "It is undoubtedly time that the powerful placebo be examined in all its myriad facets; otherwise medicine will always have a limited perception of healing." Post Modern Voices say, "Patients could benefit from clinicians maximising the potential of placebo effects associated with effective therapies." (Ernst, 2007)

II. Hawthorne effect: ('caring' as a beneficial force) A classic Harvard study in Western Electric's factory at Hawthorne during 1927-37 proved that when employees perceived that the employer "cared", productivity always improved. Hawthorne effect is relevant to all "caring" enterprises including health care. Patients "feel better" after deciding to put themselves under the care of a physician, a nurse, or a hospital. The attitudes of the management and supervisors influenced the length of hospital stay: the more supportive the management, the shorter the hospital stay. "Unfortunately, the healthcare providers and managers have, until recently, ignored these seminal ideas" (Dr Kerr White, 1996).

III. Spiritual factor and Health: The WHO definition of health was revised in 1984 by SEARO: "Health is a dynamic state of complete physical, mental, spiritual and social well-being.” (Khayat, 1998). A WHO study on Quality of Life, Spirituality, Religion \& Personal Beliefs (SRPB) involved 5087 subjects in 18 countries. SRPB factors correlated with all the Quality of Life domains. Women reported greater feelings of spiritual connection and faith than men. Less educated reported greater faith but was less hopeful. We need to assess our patients' Spirituality, Religion \& Personal Beliefs as they affect the perceived quality of life

Association of American Medical Colleges adopted Spirituality in 1999 and announced, "Spirituality is an individual's search for the ultimate meaning through participation in religion and/or belief in God, family, naturalism, rationalism, humanism, and the arts. These factors influence how patients and health care professionals perceive health \& illness and how they interact with one another."

Post Modern Views on Spirituality: Prayer is not a substitute for rational medical treatment but it is an important element in the way patients cope with chronic illness, suffering, and loss. Physicians need to address and be attentive to all suffering of their patients - be it physical, emotional, or spiritual.

\footnotetext{
* Prof. .Sethuraman MD, Vice-Chancellor, Sri Balaji Vidyapeeth, Puducherry
} 